\title{
Did you rule out neurosyphilis?
}

\author{
Ricardo Nitrini', Anderson Rodrigues Brandão de Paiva ${ }^{2}$, \\ Leonel TadaoTakada3 , Sonia Maria Dozzi Brucki ${ }^{4}$
}

\begin{abstract}
Neurosyphilis, formerly a frequent cause of dementia, is now a rare condition in developed countries. However, syphilis remains common in many developing countries, where adequate diagnosis and treatment of early syphilis may be lacking, increasing the chances of neurosyphilis and prevalence of syphilitic dementia. Objectives: To present cases of syphilitic dementia seen in a cognitive and behavioral neurology unit in Brazil, emphasizing their first symptoms and the challenges they posed in diagnosis. Methods: At our unit of the Hospital das Clínicas of the University of São Paulo, all patients are submitted to blood treponemal tests. When the test is positive, a lumbar puncture is performed. We retrospectivelly reviewed all cases of neurosyphilis seen in our unit from January 1991 to November 2009. Results: Nine cases of neurosyphilis (0.77\% of the 1160 cases in our files) were identified over the period. Patients with neurosyphilis were all men, had a mean age of 47.8 ( \pm 13.0 ) years (median of 43 years), and presented with various neuropsychiatric syndromes and elusive diagnoses. The median time from onset of symptoms to diagnosis was 24 months and only one patient made a full recovery after treatment. Conclusions: Neurosyphilis is not frequent but remains present, causing several types of neuropsychiatric syndromes. As it is very simple to rule out neurosyphilis by performing a blood treponemal test, this test should be performed in all patients with neuropsychiatric symptoms, particularly in regions of the world where syphilis is still a commonly occurring disease.
\end{abstract}

Key words: neurosyphilis, syphilis, dementia, neuropsychiatry, paretic neurosyphilis.

\section{Você excluiu neurossífilis?}

Resumo - Neurossífilis, anteriormente uma causa freqüente de demência, é atualmente rara nos países desenvolvidos. A sífilis é ainda uma doença comum em muitos países em desenvolvimento, onde o diagnóstico e tratamento da sífilis precoce podem não ser adequados, o que aumenta a possibilidade de ocorrência de neurossífilis e de demência. Objetivos: apresentar casos de demência sifilítica atendidos em uma unidade de neurologia cognitiva e do comportamento no Brasil, enfatizando os primeiros sintomas e os desafios que impuseram ao diagnóstico. Métodos: Em nossa unidade do Hospital das Clínicas da Universidade de São Paulo, todos os pacientes são submetidos a teste treponêmico no sangue. Quando o teste é positivo, é realizada punção lombar. Avaliamos retrospectivamente todos os casos de neurossífilis atendidos em nossa unidade de janeiro de 1991 a novembro de 2009. Resultados: Nove casos de neurossífilis (0,77\% dos 1.160 casos de nossos arquivos) foram identificados neste período. Os pacientes com neurossífilis eram todos homens, com idade média de 47,8 ( $\pm 13,0)$ anos (mediana de 43 anos), e apresentaram-se com vários tipos de síndromes neuropsiquiátricas, de difícil diagnóstico. O tempo médio entre o início dos sintomas e o diagnóstico foi de 24 meses e apenas um paciente teve recuperação completa após o tratamento. Conclusões: Neurossífilis não é frequente, mas ainda está presente causando vários tipos de síndromes neuropsiquiátricas. Como é muito simples excluir o diagnóstico de neurossífilis mediante teste treponêmico no sangue, este teste deve ser realizado em todo paciente com sintomas neuropsiquiátricos, particularmente nas regiões do mundo onde a sífilis é ainda uma doença comum.

Palavras-chave: neurossífilis, sífilis, demência, neuropsiquiatria, paralisia geral progressiva

\footnotetext{
${ }^{1-4} \mathrm{MD}, \mathrm{PhD}$, Behavioral and Cognitive Neurology Unit, Department of Neurology, and Cognitive Disorders Reference Center (CEREDIC), Hospital das Clínicas of the University of São Paulo School of Medicine, São Paulo SP, Brazil.
}

Ricardo Nitrini - Rua Itapeva, 378 / cj. 93 - 01332-000 São Paulo SP - Brazil. E-mail: rnitrini@uol.com.br

Disclosure: The authors report no conflicts of interest.

Received Jully 10, 2010. Accepted in final form September 11, 2010. 
Neurosyphilis was probably the most common cause of dementia until the mid-twentieth century, because syphilis was very frequent and there was no adequate treatment for early syphilis. Thus, a proportion of cases evolved to late forms, when dementia of neurosyphilis may occur. On the other hand, life expectancy was low, which meant that the degenerative dementias that are more frequent after 65 years were much rarer than today. The advent of penicillin changed this scenario, because penicillin is highly effective in the treatment of early syphilis, limiting the spread of the disease and preventing progression to late forms. ${ }^{1}$

Amongst these late forms, dementia may occur in meningovascular neurosyphilis, which may cause vascular dementia or hydrocephalus by blocking the transit of cerebrospinal fluid (CSF). But the most frequent cause of syphilitic dementia is paretic neurosyphilis (or dementia paralytica, or general paralysis of the insane or general paresis). Paretic neurosyphilis occurs in about $5 \%$ of patients untreated for early syphilis, usually from 10 to 25 years after the infection., ${ }^{2,3}$

In paretic neurosyphilis there is a chronic meningoencephalitis caused by the invasion of brain parenchyma by Treponema pallidum. The most conspicuous findings are cortical atrophy, most markedly in the anterior portions of the brain, thickening of the meninges and enlargement of the ventricles. There may be strong lymphoplasmocytic infiltrates in the meninges and its vessels, which accumulate forming a cuff in the perivascular spaces of the brain. Variable degrees of proliferation of the intimal layer with narrowing and occlusion of the vessel lumen are seen in small capillaries and venules, which are probably responsible for the marked loss of neurons, astrogliosis and microglial cells that occur in the cerebral cortex, cerebellum and basal ganglia. ${ }^{2}$ In other cases, the lymphoplasmocytic infiltrate is minor and the degenerative changes predominate with more severe cortical atrophy. ${ }^{4}$ Treponemes may be evident in the cortex in 25 to $40 \%$ of the cases, ${ }^{5}$ and are more frequent in those cases where the lymphoplasmocytic infiltrate is minor. ${ }^{4}$

The efficacy of penicillin in the treatment of early syphilis reduced the frequency of dementia caused by neurosyphilis in developed countries in such a way that in 2001 the American Academy of Neurology guidelines for the diagnosis of dementia proposed that screening for syphilis in all patients with dementia was no longer necessary. ${ }^{6}$ Dementia caused by neurosyphilis has become so uncommon in the developing world that single cases are published as case reports of rare causes of dementia, sometimes with challenging diagnosis because neuropsyphilis is not regularly included amongst diagnostic hypotheses. ${ }^{7-9}$

In Brazil, as well as in many other developing countries, syphilis is still a common disease,$^{10}$ and adequate diagnosis and treatment of early syphilis may be lacking, making syphilitic dementia more frequent. In a multicenter study in Brazil, the prevalence of syphilis in patients with mental illness was $1.12 \% .{ }^{11}$ The Brazilian Academy of Neurology recommends screening for syphilis in the diagnosis of dementia through use of blood tests. ${ }^{12}$

Diagnosing syphilitic dementia demands a considerable degree of suspicion, particularly in the initial phase, when treatment is more effective. When dementia is severe, the chances of full recovery is low. ${ }^{13}$

Our aims in this retrospective study were to present cases of patients with syphilitic dementia assisted in a cognitive and behavioral neurology unit in São Paulo, Brazil, emphasizing their first symptoms and the challenges they posed in diagnosis.

\section{Methods}

At the Behavioral and Cognitive Neurology Unit of the Hospital das Clínicas of the University of São Paulo, a public hospital, all patients are submitted to blood tests for syphilis, including a treponemal test. When the treponemal test is positive, a lumbar puncture is performed, and the diagnosis of neurosyphilis is confirmed by positive VDRL and treponemal test in CSF. When only the treponemal test is positive in the CSF, the diagnosis of neurosyphilis is still possible when there is pleocytosis $\left(\geq 5\right.$ cells $\left./ \mathrm{mm}^{3}\right)$ and/ or slightly elevated protein levels $(45-200 \mathrm{mg} / \mathrm{dL})$ with a high gammaglobulin proportion $(>14 \%)$. All patients with syphilis are tested for HIV infection.

We identified all patients with behavioral or cognitive disturbances caused by neurosyphilis that were seen in our unit from January 1991 to November 2009.

The cases of neurosyphilis were analyzed with respect to demographic characteristics, main symptoms and signs, duration of symptoms until diagnosis, neuropsychological profile and exams. The classification of the forms of neurosyphilis into general paresis, taboparesis or meningovascular syphilis was based on guidelines proposed by Merritt et al. ${ }^{2}$ All patients were treated with intravenous penicillin at high doses and treatment outcomes were evaluated.

This study was approved by the Research Ethics Committee of the Hospital das Clínicas of the University of São Paulo, Brazil.

\section{Results}

In this 19 -year period, 1,160 patients ( $54.6 \%$ women) presenting cognitive or behavioral disturbances, with a mean age of $68.3( \pm 11.6)$ years and $5.6( \pm 4.6)$ years of schooling, were assisted at our unit. Nine cases of neurosyphilis $(0.77 \%)$ were identified in this period. Patients 
Table 1. Demographic data, diagnoses and time to diagnosis.

\begin{tabular}{cccccc}
\hline Case/Year & Gender & Age & $\begin{array}{c}\text { Education } \\
\text { (years of schooling) }\end{array}$ & $\begin{array}{c}\text { Diagnosis } \\
\text { (clinical syndrome) }\end{array}$ & $\begin{array}{c}\text { Time to diagnosis } \\
\text { (months) }\end{array}$ \\
\hline $1 / 1991$ & $\mathrm{M}$ & 32 & 15 & PN & 36 \\
$2 / 1993$ & $\mathrm{M}$ & 61 & 1 & PN & 17 \\
$3 / 1994$ & $\mathrm{M}$ & 43 & 15 & PN & 12 \\
$4 / 1997$ & $\mathrm{M}$ & 42 & 4 & $\mathrm{MV}$ & 24 \\
$5 / 1997$ & $\mathrm{M}$ & 48 & 5 & TP & 12 \\
$6 / 1995$ & $\mathrm{M}$ & 36 & 16 & PN & 6 \\
$7 / 2000$ & $\mathrm{M}$ & 59 & 16 & $\mathrm{PN}$ & 24 \\
$8 / 2000$ & $\mathrm{M}$ & 39 & 0 & PN & 48 \\
$9 / 2003$ & $\mathrm{M}$ & 71 & & & 36 \\
\hline
\end{tabular}

MV: meningovascular neurosyphilis; PN: paretic neurosyphilis; TP: taboparesis.

Table 2. First blood tests and cerebrospinal fluid (CSF) examinations.

\begin{tabular}{|c|c|c|c|c|c|c|c|}
\hline \multirow[b]{2}{*}{ Case } & \multicolumn{2}{|r|}{ Serum } & \multicolumn{5}{|c|}{ CSF } \\
\hline & VDRL & Trep. T. & Leukoc/mm ${ }^{3}$ & Protein $(\mathrm{mg} / \mathrm{dl})$ & Gammagl. (\%) & VDRL & TPHA \\
\hline 1 & $1 / 8$ & $\mathrm{TPHA}+(>1 / 1024)$ & 13 & 76 & 49.7 & $1 / 8$ & $>1 / 1024$ \\
\hline 2 & $1 / 16$ & FTA-Abs + & 10 & 64 & 20.3 & $1 / 4$ & $>1 / 1024$ \\
\hline 3 & NA & FTA-Abs + & 58 & 50 & 26.3 & WR $1 / 4$ & $1 / 512$ \\
\hline 4 & $1 / 1$ & FTA-Abs + & 36 & 98 & 31.3 & $1 / 4$ & + \\
\hline 5 & NA & FTA-Abs + & 5 & 60 & 42.6 & + & + \\
\hline 6 & $1 / 8$ & $\mathrm{TPHA}+(1 / 256)$ & 3 & 33 & 35.9 & $1 / 2$ & $1 / 256$ \\
\hline 7 & $1 / 32$ & FTA-Abs + & 165 & 127 & 31.8 & $\mathrm{WR}+$ & $1 / 512$ \\
\hline 8 & NR & ELISA + & 45 & 70 & 39.6 & + & $1 / 512$ \\
\hline 9 & $1 / 256$ & TPHA + & 133 & 206 & 33.9 & $1 / 128$ & + \\
\hline
\end{tabular}

ELISA: Enzyme linked immunoassay; FTA-Abs: fluorescent treponemal antibody-absorbed; Gammagl.: gammaglobulin; Leukoc: leukocytes; NA: not available; NR: Non reactive; WR: Wassermann's reaction; TPHA: Treponema pallidum haemagglutination assay.

with neurosyphilis were all men, had a mean age of 47.8 $( \pm 13.0)$ years (median of 43 years), and $8.8( \pm 6.6)$ years of schooling (median of 8 years of schooling). Demographic data and diagnoses are shown in Table 1. Median time to diagnosis from onset of symptoms was 24 months. Seven cases were diagnosed as paretic neurosyphilis, one with taboparesis (paretic neurosyphilis with tabetic signs) and one case as meningovascular neurosyphilis.

One patient (case 4) reported a history of syphilis. The neurological examination disclosed hyperactive deep reflexes in six cases (cases 1,2,3,4,5,9) dysarthria in four cases (cases 1,3,4,8), hemiparesis in three (cases 2,5,6), and absence of the light reflex with an active reaction in accommodation (Argyll Robertson pupil) in two cases (cases 1, 6). One patient (case 9) had parkinsonian signs. Beyond the cognitive and behavioral abnormalities, the neurological examination did not disclose other signs in one patient (case 7), while subtle signs were seen in cases 1 and 8.
Serum and CSF tests are shown in Table 2. All patients had positive non-treponemal tests (VDRL or Wassermann's test) in the CSF and eight presented with pleocytosis.

Table 3 contains a summary of the initial symptoms, the presumptive or first diagnostic hypothesis, and outcome after treatment with intravenous penicillin from 18 to 24 million IU for 10 to 21 days. Only one case made a full recovery, returning to his previous professional activities. In most cases there was a partial recovery or the condition was considered to be unchanged when the progression of the disease was halted without significant improvement.

Table 4 summarizes neuroimaging data. Vignettes of the nine cases are presented in the appendix.

\section{Discussion}

Our findings show that syphilitic dementia still occurs in our country, albeit at a much lower frequency compared to levels reported before penicillin became available. ${ }^{2}$ 
Table 3. Initial symptoms, first diagnostic hypothesis, Mini-Mental State Exam (MMSE) and outcome.

\begin{tabular}{|c|c|c|c|c|c|}
\hline Case & Initial symptoms & $\begin{array}{l}\text { First diagnostic } \\
\text { Hypothesis }\end{array}$ & $\begin{array}{c}\text { Initial } \\
\text { MMSE score }\end{array}$ & Outcome & $\begin{array}{l}\text { Highest MMSE score } \\
\text { after treatment }\end{array}$ \\
\hline 1 & $\begin{array}{l}\text { Persecutory delusions, auditory } \\
\text { hallucinations and epileptic seizures }\end{array}$ & $\begin{array}{l}\text { Psychosis, } \\
\text { schizophrenia }\end{array}$ & 23 & Unchanged & 22 \\
\hline 2 & $\begin{array}{l}\text { "Meningoencephalitis", memory } \\
\text { decline, topographical disorientation }\end{array}$ & $\begin{array}{c}\text { Herpetic } \\
\text { encephalitis }\end{array}$ & NA & Unchanged & 19 \\
\hline 3 & $\begin{array}{l}\text { Irritability, motor and psychic } \\
\text { slowness }\end{array}$ & $\begin{array}{l}\text { "Organic" } \\
\text { disorder }\end{array}$ & 11 & $\begin{array}{c}\text { Partial } \\
\text { improvement }\end{array}$ & 29 \\
\hline 4 & Tremors, seizures, memory decline & $\begin{array}{l}\text { Cerebrovascular } \\
\text { disease }\end{array}$ & 17 & $\begin{array}{l}\text { Partial } \\
\text { improvement }\end{array}$ & 23 \\
\hline 5 & $\begin{array}{l}\text { Forgetfulness, dysexecutive } \\
\text { syndrome, seizures }\end{array}$ & $\begin{array}{c}\text { Dementia } \\
\text { not specified }\end{array}$ & 25 & Unchanged & 25 \\
\hline 6 & $\begin{array}{l}\text { Agressivity, memory decline, } \\
\text { collecting behavior }\end{array}$ & $\begin{array}{c}\text { Dementia } \\
\text { not specified }\end{array}$ & 0 & $\begin{array}{c}\text { Partial } \\
\text { improvement }\end{array}$ & 25 \\
\hline 7 & $\begin{array}{l}\text { Memory decline, topographical } \\
\text { disorientation, social inadequacy }\end{array}$ & Alzheimer's disease & 22 & Full recovery & 27 \\
\hline 8 & $\begin{array}{l}\text { Irritability, social withdrawal, } \\
\text { dysexecutive syndrome }\end{array}$ & $\begin{array}{l}\text { Frontotemporal } \\
\text { dementia }\end{array}$ & 29 & Unchanged & 29 \\
\hline 9 & $\begin{array}{l}\text { Delirium, tremors, memory decline, } \\
\text { topographical disorientation }\end{array}$ & $\begin{array}{l}\text { Dementia with } \\
\text { Lewy bodies }\end{array}$ & 10 & $\begin{array}{c}\text { Partial } \\
\text { improvement }\end{array}$ & 13 \\
\hline
\end{tabular}

Table 4. Neuroimaging findings.

\begin{tabular}{|c|c|c|}
\hline Case & $\begin{array}{l}\text { Computed tomography }(\mathrm{CT}) \\
\text { Magnetic resonance imaging }(\mathrm{MRI})\end{array}$ & Single Photon computed tomography (SPECT) \\
\hline 1 & NA & Slight hypoperfusion in the left fronto-parietal cortex \\
\hline 2 & CT: Normal & \\
\hline 3 & MRI: Cortical atrophy, more severe in the right hemisphere & NA \\
\hline 4 & $\begin{array}{l}\text { CT: Multiple infarcts (larger infarct in the right } \\
\text { temporoparietal area) }\end{array}$ & $\mathrm{NA}$ \\
\hline 5 & $\begin{array}{l}\text { MRI: Diffuse cortico-subcortical atrophy and infarct } \\
\text { in the right temporal lobe }\end{array}$ & NA \\
\hline 6 & CT: Diffuse cortico-subcortical atrophy & NA \\
\hline 7 & CT: Diffuse cortico-subcortical atrophy & NA \\
\hline 8 & MRI: Diffuse cortico-subcortical atrophy & Slight hypoperfusion in the frontal cortex. \\
\hline 9 & MRI: Diffuse cortico-subcortical atrophy & $\mathrm{NA}$ \\
\hline
\end{tabular}

NA: not available.

All patients in this series were men. Syphilis, and particularly neurosyphilis, has always been more frequent in men since its first descriptions. In the past, syphilis was considered to be more common in men because they were infected by women prostitutes, with many men being infected by a few prostitutes. ${ }^{14}$ More recently, syphilis has been more frequent in men who have sex with other men. ${ }^{15}$ Syphilis and neurosyphilis have also been more frequent in HIV+ patients. ${ }^{16}$ In this series, none of the patients were HIV+, probably because there is a referral bias, with HIV + patients being assisted in other departments of our hospital.

There are several aspects that need to be stressed. Most of our patients were younger than 50 years old and can be classified as young-onset dementia. ${ }^{17}$ The time from the 
initial symptoms to the diagnosis of neurosyphilis (median of 24 months) was very long. This may be in part explained by the protean early symptoms. The presumptive diagnoses were diverse, ranging from schizophrenia to herpetic encephalitis, with many cases being attributed to degenerative or unspecified causes. Neurosyphilis has been long recognized as a "great imitator", ${ }^{18}$ and the clinical diagnosis can be very difficult because "pure psychiatric cases" may be found or other diagnoses may be entertained.

Previous history of syphilis is rarely obtained in these cases, and in this study, only one patient reported a history of syphilis. The neurological examination may show hyperactive deep reflexes, hemiparesis, dysarthria, pupillary abnormalities and absence of the light reflex, and even parkinsonian signs. In this series, "somatic" neurological examination was normal in only one patient, with only subtle signs in two.

Neuroimaging, the most important subsidiary exam for the diagnosis of dementia, may be misleading in paretic neurosyphilis because the diffuse atrophy may be suggestive of degenerative dementia. ${ }^{19}$ In this small series, five cases had CT or MRI showing diffuse cortico-subcortical atrophy without other findings.

In a study performed in New Orleans, Louisiana, USA, the authors reviewed all cases of neurosyphilis seen in a university hospital from 1998 to 2001. Cases with positive-HIV serology were excluded. They found 17 cases of neurosyphilis, with mean age of $49.7( \pm 12.0)$ years. Neuropsychiatric symptoms were frequent (four presented with violent behavior, six were disoriented, and four had memory deficits). ${ }^{20}$

As evidenced, neurosyphilis is not a rare disease, but its diagnosis may be very elusive. However, it is easy to rule out this diagnosis using blood tests. Serum VDRL may be non reactive in neurosyphilis, but a negative treponemal test (FTA-Abs: fluorescent treponemal antibody-absorbed or TPHA: Treponema pallidum haemagglutination assay or ELISA: Enzyme linked immunoassay) virtually excludes syphilis. ${ }^{19}$ If serum treponemal antibody test is reactive in a suspected case of neurosyphilis, lumbar puncture is mandatory. A non-reactive treponemal test in the CSF virtually excludes neurosyphilis. Although the CSF-treponemal tests have high sensitivity, their specificity is not high, as a reactive test may be due to diffusion of antibodies from the serum. When a CSF-treponemal test is reactive, the diagnosis of neurosyphilis is supported by reactive CSF-VDRL, which is highly specific, though false reactive CSF-VDRL may occur when there is blood in the CSF or when the blood-brain barrier is severely breached. However, as its sensitivity is relatively low, false negative CSF-VDRL tests may occur in neurosyphilis. ${ }^{16,19}$ When the CSF treponemal test is reactive and the CSF-VDRL is non-reactive, diagnosis of neurosyphilis is supported by pleocytosis ( $\geq 5$ cells/ $\left.\mathrm{mm}^{3}\right)$, slightly elevated protein $(45-200 \mathrm{mg} / \mathrm{dL})$ with elevated CSF-IgG. The diagnosis may be particularly difficult in patients with HIV-1 infection because slight pleocytosis and elevated protein in the CSF are also common in this condition. Given that syphilis is common in HIV-infected individuals, a reactive FTA-Abs test in the CSF could be caused by diffusion from the serum, in the absence of neurosyphilis. If a patient with possible paretic neurosyphilis has a reactive CSF-treponemal test and pleocytosis or elevated protein concentration, even if the CSF-VDRL is negative, treatment for neurosyphilis should be given. ${ }^{16,19}$ This is particularly relevant for patients with HIV-1 infection. ${ }^{16}$

In our cases, serum VDRL was non-reactive in one case whereas serum and CSF treponemal tests were reactive in all patients. CSF-VDRL was reactive in all cases in which it was performed ( 7 cases). In the other two patients, VDRL was substituted by the Wassermann's complement fixation test, which was reactive in both cases (Table 2). Pleocytosis was present in seven cases and high concentration of protein in the CSF in eight cases. A very high proportion of gammaglobulins $(>30 \%$ ), which are mostly IgG, was found in seven cases. High levels of IgG is a frequent finding in neurosyphilis, particularly in paretic dementia. ${ }^{21}$

All patients were treated with intravenous penicillin $G$ for 10 to 21 days. In our service we treat patients with severe forms of neurosyphilis with 24 million international units of penicillin $\mathrm{G}$ for 21 days. In this series, a few patients that came to our service after recent treatment had received intravenous penicillin for 10 to 14 days. All patients were followed-up with lumbar puncture repeated at 6-month intervals for 2 to 3 years. No cases had persistent pleocytosis, and no patients were re-treated with antibiotics for neurosyphilis.

In neurosyphilis, significant clinical improvement occurs mainly when the treatment is administered in the first few months after the onset of the mental disturbances, particularly in mild and moderate disturbances. ${ }^{2,13}$ In our series however, only one patient returned to his previous professional activity whereas most patients became dependent on others or were able to work only in less demanding activities. This may be explained by the long delay reaching diagnosis, in a condition where the diagnosis is so simple, when only a blood treponemal test need be performed.

The main conclusions of this paper are: [i] neurosyphilis is not frequent but it is still present, causing many types of neuropsychiatric syndromes, from schizophreniform psychotic syndrome to dementia mimicking Alzheimer's disease; [ii] as it is very simple to rule out neurosyphilis by performing a blood treponemal test, this test should be 
performed in all patients with neuropsychiatric symptoms, particularly in regions of the world where syphilis is still a common disease.

\section{References}

1. Nitrini R. The cure of one of the most frequent types of dementia: a historical parallel. Alzheimer Dis Assoc Disord 2005;19:156-158.

2. Merritt HH, Adams RD, Solomon HC. Neurosyphilis. York, New York, Oxford University Press New; 1946.

3. Hahn RD, Webster B, Weickhardt G, et al. The results of treatment in 1,086 general paralytics the majority of whom were followed for more than five years. J Chronic Dis 1958;7: 209-227.

4. Miklossy J. Biology and neuropathology of dementia in syphilis and lyme disease. Handb Clin Neurol 2008;89:825-844.

5. Hook III EW. Central Nervous System Syphilis. In: WM Scheld, RJ Whitley, DT Durack (Eds.), Infections of the central nervous system. Raven Press, Ltd., New York, 1991;27: 639-655.

6. Knopman DS, DeKosky ST, Cummings JL, et al. Practice parameter: diagnosis of dementia (an evidence-based review): report of the Quality Standards Subcommittee of the American Academy of Neurology. Neurology 2001; 56:1143-1153.

7. Lee JW, Wilck M, Venna N. Dementia due to neurosyphilis with persistently negative CSF VDRL. Neurology 2005;65: 1838 .

8. Lee $\mathrm{CH}$, Lin WC, Lu CH, Liu JW. Initially unrecognized dementia in a young man with neurosyphilis. Neurologist 2009; 15:95-97.

9. Güler E, Leyhe T. A late form of neurosyphilis manifesting with psychotic symptoms in old age and good response to ceftriaxone therapy. Int Psychogeriatr 2010;15:1-4.
10. World Health Organization. Global prevalence and incidence of selected curable sexually transmitted infections: overview and estimates. Geneva: World Health Organization; 2001.

11. Guimarães MD, Campos LN, Melo AP, et al. Prevalence of HIV, syphilis, hepatitis B and C among adults with mental illness: a multicenter study in Brazil. Rev Bras Psiquiatr 2009;31: 43-47.

12. Nitrini R, Caramelli P, Bottino CM, Damasceno BP, Brucki SM, Anghinah R. [Diagnosis of Alzheimer's disease in Brazil: diagnostic criteria and auxiliary tests: recommendations of the Scientific Department of Cognitive Neurology and Aging of the Brazilian Academy of Neurology]. Arq Neuropsiquiatr 2005;63:713-719.

13. Storm-Mathisen A. Syphilis. In: PJ Vinken, GW Bruyn (Eds.), Infections of the Nervous System, part I. Handbook of Clinical Neurology, (1978) Vol. 33, pp. 337-394. Amsterdam: Elsevier.

14. Rocha F, Pacheco-Silva AC. A demência paralytica em São Paulo, Arq Brasil Neuriat Psiquiat 1924:6:1-22.

15. Kahn RH, Heffelfinger JD, Berman SM. Syphilis outbreaks among men who have sex with men: a public health trend of concern. Sex Transm Dis 2002;29:285-287.

16. Marra CM. Update on neurosyphilis. Curr Infect Dis Rep 2009;11:127-134.

17. Rossor MN, Fox NC, Mummery CJ, Schott JM, Warren JD. The diagnosis of young-onset dementia. Lancet Neurol 2010; 9:793-806.

18. Synnott IH. The great imitator. Med J Aust 1988;148:105.

19. Nitrini R. Clinical and therapeutic aspects of dementia in syphilis and lyme disease. Handb Clin Neurol 2008;89:819-823.

20. Lair L, Naidech AM. Modern neuropsychiatric presentation of neurosyphilis. Neurology 2004;63:1331-1334.

21. Nitrini R, Spina-França A. [High-dose intravenous penicillin therapy in neurosyphilis: study of 62 cases. II. Evaluation of cerebrospinal fluid]. Arq Neuropsiquiatr 1987;45:231-241. 


\section{APPENDIX}

\section{A summary of each case is presented below}

Case \# 1. A 32 year-old man, a publicity designer, had a psychotic episode with persecutory delusions three years before being seen at our unit. He improved with haloperidol, but two years later these symptoms reappeared, with auditory and visual hallucinations. Haloperidol, even at low doses, caused adverse extrapyramidal effects. A month before his first visit to our unit he had a tonic-clonic seizure, and a lumbar puncture disclosed neurosyphilis. He was treated with intravenous penicillin G, 24 million international units (IU) per day for 15 days. In our unit, immediately after treatment, he scored 23 on the Mini-Mental State Exam (MMSE), 8 in the semantic verbal fluency test (animals in one minute), and in the digit span was able to repeat 4 digits forwards and 3 backwards. He had impairments in delayed memory, abstraction and calculation, but language and praxis were normal. On the "somatic" neurological examination, he had Argyll Robertson pupils, hyperactive palmomental reflex on both sides, slight hand tremors, hyperactive deep reflexes without Babinski sign, and mild dysarthria. Repeated lumbar punctures after treatment showed that neurosyphilis had been successfully treated. Test for HIV-1 infection was negative. During almost 20 years of follow-up this patient had a few psychotic crises and epileptic seizures that were successfully treated. He remained unable work.

Case \# 2. A 61 year-old estate-agent had an acute confusional state with visual hallucinations and left hemiparesis shortly after having abandoned alcohol abuse. He was submitted to a lumbar puncture that revealed pleocytosis. Herpetic meningoencephalitis was suspected and he was treated accordingly. Nine months later, he progressively developed memory decline and topographical disorientation. Three months later, he had an episode of generalized hypertonia and confusion. Neurologic examination revealed left hemiparesis and exacerbated axial reflexes. A lumbar puncture disclosed neurosyphilis and he was treated with intravenous penicillin G, 24 million IU per day for 21 days. Test for HIV-1 infection was negative. At follow-up, lumbar punctures showed that treatment with penicillin was adequate, but one year after treatment, he was placed in care at a hospice and persisted with psychotic symptoms.

Case \# 3. A 43-year-old school teacher progressively developed irritability, difficulty moving his left side and memory loss one year before being seen at our unit. His speech became monotonous and he stopped planning his classes. A psychiatric evaluation revealed an organic disorder. A lumbar puncture revealed neurosyphilis and he was treated with intravenous penicillin G, 18 millions IU per day for 10 days. Test for HIV-1 infection was negative. Our first evaluation was after treatment. His past medical history was unremarkable, except for arterial hypertension. Neurologic examination revealed flexed posture, mild dysarthria and tongue tremor, hyperactive axial and deep reflexes. A new course of penicillin was indicated - intravenous penicillin G, 24 million IU per day, for 21 days. At follow-up, repeated lumbar punctures showed that treatment with penicillin was adequate. Despite an obvious improvement in his MMSE score, he was unable to return to work because of the persistence of his behavioral symptoms and was dependent on antipsychotic drugs.

Case \# 4. A 42 year-old retired electrician was evaluated in August 1997. Two years previous, a voice tremor was noticed. This tremor progressively spread through the body. One year before the initial evaluation, he started to present recurrent seizures. His family noticed memory loss. His past medical history was relevant for alcoholism, a stroke at 35 years old and chancre at 22 years of age. A sudden left hemiparesis took place in January 1997. Neurologic examination disclosed attention impairment, as well as in abstraction and visual and constructive abilities, besides left hemiparesis. A lumbar puncture revealed neurosyphilis and he was treated with intravenous penicillin G, 24 million IU per day for 21 days. Test for HIV-1 infection was negative. Seven months after treatment, lumbar puncture showed that the treatment with penicillin had been adequate but the cognitive and somatic examinations were unchanged.

Case \#5. A 48-year-old man, with 8 years of schooling, worked as a salesman in Brazil, but for the last few years had been working as an industrial laborer in Japan, while his wife and children were still living in Brazil. About a year before being seen at our unit, he started to have difficulties in performing his work and presented memory impairment. He had a seizure and was treated with antiepileptic drugs, subsequently returning to Brazil. On examination, he was apathetic with mild expressive aphasia and mild right hemiparesis. He scored 25 on the MMSE, 9 on the semantic verbal fluency test (animals in one minute), only 
3 on the delayed recall test (normal: 6-10) while in the digit span he was able to repeat 4 digits forwards and 2 backwards. A lumbar puncture revealed neurosyphilis and he was treated with intravenous penicillin G, 24 million IU per day for 21 days. Test for HIV-1 infection was negative. In the follow-up, repeated lumbar punctures revealed that the treatment with penicillin had been adequate but his mental state did not improve and he manifested episodes of depression and persecutory delusions, requiring antidepressants and antipsychotics.

Case \# 6. A 38-year-old, working in a truck mechanic's shop, was seen in August 1997. Thirty months before the first office visit, memory loss and personality changes were observed together with aggressiveness, poor self-hygiene, incoherent speech and collectionism (garbage and worthless objects). He progressively became infantilized. Six months after the initial symptoms, a gait disorder became evident and focal seizures occurred. His past medical history was unremarkable. On examination, he was severely apathetic, unable to collaborate with the examiner, bedridden, with mild left hemiparesis, frontal releasing signs and arreflexia in the lower limbs. A lumbar puncture revealed neurosyphilis and he was treated with intravenous penicillin G, 24 million IU per day for 21 days. The test for HIV-1 infection was negative. At discharge from the first hospitalization, he was able to walk and tabetic signs were evident, besides a frontal syndrome. Follow-up with lumbar punctures showed that neurosyphilis had been adequately treated. In 13 years of follow-up he persisted with fluctuations in his behavioral symptoms and needed control of seizures. He was able to work in a lowly position in his brother's truck repair business.

Case \# 7. A 59-year-old lawyer manifested difficulties learning new pieces of information and remembering where he had left objects, over a period of two years. One year after the initial symptoms he had several minor car accidents. He manifested odd behaviors such as eating in the bathroom and drove at disproportionally low speed on the highway. Three months before the initial examination he was easily irritable and urinated in his boss's office and was dismissed. Past medical history: moderate alcohol consumption. There was no history of syphilis. Familial history: unremarkable. On examination, his "somatic" neurological examination was normal; he scored 25 on the MMSE, 6 on the semantic verbal fluency test (animals in one minute), and only 3 on the delayed recall test (normal: 6-10). A lumbar puncture revealed neurosyphilis and he was treated with intravenous penicillin G, 24 million IU per day for 21 days. Test for HIV-1 infection was negative. Two months after his treatment, he returned to his professional activities.

Case \# 8. A 39-year-old man, a human resources executive, presented with a 4-year history of irritability and social withdrawal followed by difficulties in professional activities and obsessive-compulsive behaviors. One year after onset, a psychiatrist diagnosed "stress and depression". One year later, he had two rapidly reversible episodes of leg paralysis. After a lumbar puncture, the diagnosis of viral meningitis was disclosed. Test for HIV-1 infection was negative. His behavior deteriorated and became more childish and he presented decreased attention, and memory impairment. In our unit, neurologic examination revealed only dysarthria. He scored 29 on the MMSE, 31 on the semantic verbal fluency test (animals in one minute), 5 on the delayed recall test (normal: 6-10), and on the digit span was able to repeat 4 digits forwards and 3 backwards. A lumbar puncture disclosed neurosyphilis and he was treated with intravenous penicillin G, 24 million IU per day for 21 days. Repeated CSF examinations showed that penicillin treatment had been successful, but during an eight-year followup period his executive dysfunction did not to improve and he had episodes of depression, increased anxiety and even delusions with persecutory ideation. He was unable to work or to lead an independent life.

Case 9. A 71-year-old man who worked as a cleaner, had an episode of night delirium, after which he was left with hand tremors, three years before being seen at our unit. One year before diagnosis he developed a rapidly progressive cognitive decline with memory impairment and topographical disorientation together with episodes of agitation, aggressiveness, visual and auditory hallucinations. He also manifested a decrease in the speed of movements. In the preceding few months he had lost sphincter control. He had high blood pressure and type II diabetes mellitus. On examination he had facial hypomimia, bradykinesia, paratonic rigidity, apraxic gait, postural and action tremors in the hands, and tremors in the chin. Deep reflexes were brisk, without Babinski sign. He scored 10 on the MMSE. Lumbar puncture revealed neurosyphilis, and he was treated with intravenous penicillin G, 24 million IU per day for 14 days. Test for HIV-1 infection was negative. At follow-up, CSF examinations showed that neuropsyphilis was adequately treated. One year after treatment, he was able to go to the nearest grocers without getting lost, but scored only 13 on the MMSE and was unable to return to his previous professional activities. 